\title{
Trends for rotavirus acute gastroenteritis in children under 5 years old before and after vaccine introduction, Morocco, 2006-2014
}

Hind Ezzine, ${ }^{1,2}$ Ahmed Rguig, ${ }^{2}$ Mariam Naciri ${ }^{1}$ and I. Jroundi ${ }^{3}$

${ }^{1}$ Research Center (BIOBIO), Laboratory of Biodiversity, Ecology and Genome, Faculty of Sciences, Mohamed V University in Rabat, Morocco. ${ }^{2}$ Directorate of Epidemiology and Diseases Control, Ministry of Health, Rabat, Morocco. ${ }^{3}$ Training and Research in Public Health and Social Accountability Unit, School of Medicine and Pharmacy, Mohammed V University, Rabat, Morocco (Correspondence to: Hind Ezzine: ezzinehind@gmail.com).

\begin{abstract}
Background: In Morocco, acute gastroenteritis in children is a public health issue. Since 1987, several strategies have been conducted to reduce its burden by the Moroccan Ministry of Health, including the introduction of the anti-rotavirus vaccine into the national immunization programme in 2010.

Aims: To evaluate the impact of the anti-rotavirus vaccine in outpatients and inpatients with acute gastroenteritis under 5 years old.

Methods: We conducted descriptive studies and a retrospective cohort study using data from the hospital's sentinel surveillance system and the national ambulatory surveillance registry for acute gastroenteritis from 2006 to 2014 . This include the period before and after the implementation of the rotavirus (RV) vaccine on children under age 5 years.

Results: The decrease in acute gastroenteritis cases was about 5.2\%, mainly among children aged o-11 months. The proportion of acute RV gastroenteritis (RVGE) decreased from $37.0 \%$ to $31.1 \%$ after the vaccine's introduction; it was statistically significant among the children aged $0-11$ months $(38.8 \%$ to $28.1 \%$; $P=0.009)$. The proportion of RVGE among inpatients decreased from $97.0 \%$ to $91.7 \%(P=0.022)$. Diarrheal disease cases without dehydration increased from $7.8 \%$ to $11.1 \%$ $(P<0.001)$; RVGE was 2.3 times more frequent among unvaccinated children. The vaccine effectiveness was estimated at $57 \%$. The proportion of $\mathrm{GlP}[8]$ genotype infections decreased after the introduction of the $\mathrm{RV}$ vaccine $(56 \%$ to $40 \%$; $P$ $<0.001$ ), while the $\mathrm{G}_{2} \mathrm{P}[4]$ genotype became more frequent $(13 \%$ to $21 \% ; P=0.015)$.

Conclusions: The introduction of the RV vaccination into the national immunization programme in Morocco has allowed significant reduction in the incidence and severity of RVGE among children under 5 years old.

Keywords: acute gastroenteritis, rotavirus vaccine, children, immunization programme, Morocco

Citation: Ezzine H; Rguig A; Naciri M; Jroundi I. Trends for rotavirus acute gastroenteritis in children under 5 years old before and after vaccine introduction, Morocco, 2006-2014. East Mediterr Health J. 2021;27(6):553-562. https://doi.org/10.26719/2021.27.6.553

Received: 24/01/19, accepted: 10/08/20

Copyright ( ) World Health Organization (WHO) 2021. Open Access. Some rights reserved. This work is available under the CC BY-NC-SA 3.0 IGO license (https://creativecommons.org/licenses/by-nc-sa/3.o/igo)
\end{abstract}

\section{Introduction}

Rotavirus remains the most common cause of severe childhood diarrhoea in developing countries. Indeed, the World Health Organization (WHO) estimates that 527000 children under the age of 5 years die of rotavirus (RV) disease each year, and these deaths occur predominantly in the poorest countries (1). The WHO recommends that RV vaccines should be included in all national immunization programmes, particularly in countries with high RV gastroenteritis-associated fatality rates (2).

Against the background of the introduction of the rotavirus vaccine into the Moroccan National immunization programme, a sentinel surveillance network of acute RV gastroenteritis (RVGE) was set up in 2006 at 5 hospitals in different regions of Morocco (3-5). The sentinel sites included paediatric departments at selected regional hospitals in north, east and central Morocco (Tangier, Oujda, Rabat, Casablanca, Beni Mellal) to discover the most severe cases of acute gastroenteritis (AGE). In 2009, the surveillance system was extended to the primary health care services to include within the ongoing surveillance system any AGE patients not admitted to hospitals. In parallel, the evaluation of the rotavirus surveillance system alerted that there was a slackening of the RVGE surveillance system in some sites (6), except in the Oriental region in eastern Morocco, represented by the city of Oujda, which was the best performing sentinel surveillance site (3-5).

The anti-RV vaccine was introduced into Morocco's national immunization programme in December 2010 (7). It is a live attenuated vaccine of human RV, monovalent, orally administered in 2 doses at ages 2 and 3 months. Since the introduction of the vaccine, no studies have been conducted to evaluate effect on the incidence of AGE using both clinical data and laboratory data; however, a concomitant study has documented the effect of monovalent RV vaccine on RV disease burden and circulating RV strains among children in Morocco using only laboratory data (8). At the end of 2014, the monovalent vaccine was replaced by a pentavalent vaccine, and virological surveillance of rotavirus has seen a reduction.

The aim of this study was to evaluate the impact of the RV vaccine among Moroccan children on: the global 
trend of AGE in Morocco among children under 5 years; the epidemiological profile of in- and outpatients with AGE in the sentinel sites; and the characteristics of circulating RV.

\section{Methods}

\section{Data sources}

Data on the burden and characteristics of RVGE in children were extracted from a number of sources. Table 1 gives an overview of the data sources used to evaluate the impact of the anti-RV vaccine implementation over a period of 8 years (June 2006 to April 2014; 2010 was excluded since it was the year of implementation of the vaccination, with a disparity between the regions of Morocco). Results are presented according to 3 steps related to distinct data sources and the availability of the clinical, laboratory and overall AGE characteristics.

\section{Study design and population}

\section{STEP 1: Global trend of AGE in Morocco among children under 5 years old}

This included all patients under 5 years old presenting with AGE, regardless of the cause, in all primary health care facilities before and after the introduction of the RV vaccine.

The aim of this part of the study was to define the progressive trends of ambulatory patients presenting with AGE in all primary health care facilities in Morocco before and after implementation of the anti-RV vaccine.

\section{STEP 2: Trend of confirmed RVGE among children under 5 years old}

This included the population of the Oriental region sentinel site before and after the implementation of the anti- $R V$ vaccine. The objectives were to evaluate the number of in- and outpatients under 5 years old with confirmed RVGE; determine the epidemiological and clinical characteristics for children under 5 years old with confirmed RVGE; and estimate the proportion of RV-positive samples.

\section{STEP 3: Rotavirus vaccine effectiveness among Moroccan children under 5 years old}

A retrospective cohort study was carried out on children under 5 years old presenting with RVGE (suspected or confirmed) who attended primary health care facilities or were admitted to Oujda hospital between 1 January 2011 and 30 April 2014. Children with unknown vaccination status or laboratory results were excluded.

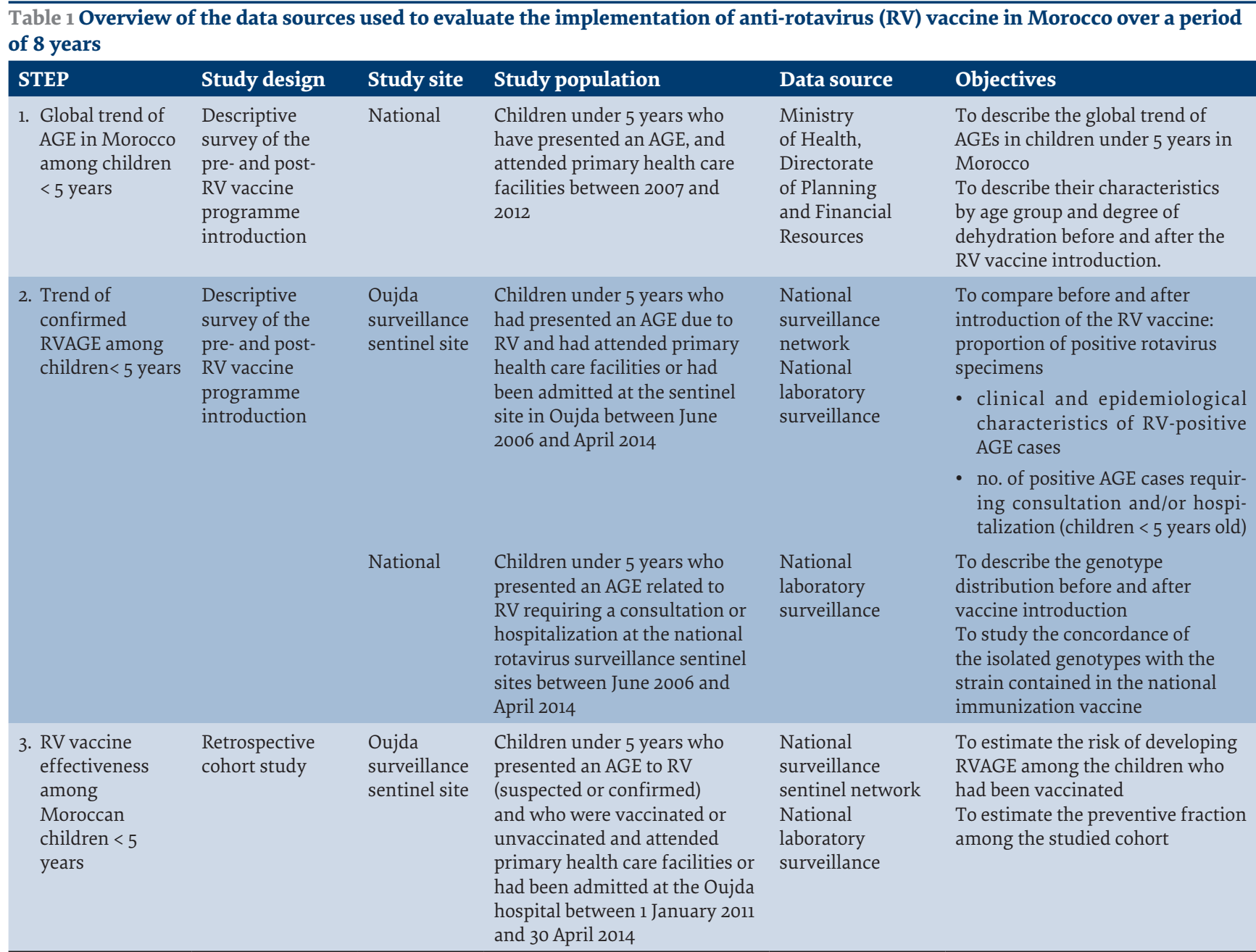


The aim of this step was to estimate the vaccine effectiveness.

\section{Case definition}

\section{Acute gastroenteritis:}

Two case definitions were used:

- In the first step of our study, we employed the case definition used by the department in charge of the primary health care and hospital morbidity statistics in the Ministry of Health. This is the Integrated Management of Childhood Illness definition (9) which defines AGE as: "Any child under the age of 5 years with a diarrheal episode which lasts less than 14 days, started on the first day when the child presents at least 3 liquid or loose stools, and the last day is when stools return to normal aspect".

- For the 2nd and 3rd steps, the sentinel RV surveillance used the WHO definition for RVGE (10):

- suspected case of RVGE: any child under the age of 5 years old who visits a health care facility or is admitted into one of the designated hospitals for an AGE;

- AGE: acute episode ( $\leq 7$ days before the consultation) with these clinical signs: fluid or loose diarrhoea $>3$ stools/24 hours (and/or vomiting $\geq 2 / 24$ hours, not explained by any other condition);

- confirmed case of RVGE: any suspected case for whom an in-laboratory stool examination, using the ELISA technique, reveals the presence of RV.

\section{Definition of vaccination status}

We considered children as vaccinated if they had received at least 2 doses of the RV vaccine. These data were collected by the RVGE surveillance network from the vaccination book, the primary health care facility vaccination registry or the mother's interview, or from any other family member who knew the vaccine status.

\section{Cohort definition (Oujda site)}

We conducted a cohort study in the Oriental region because the surveillance system evaluation indicated good performance there. The cohort comprised children under 5 years old who met the case definition of RV (suspected or confirmed), and who attended the Oriental region's site for an ambulatory consultation or had been admitted between 1 January 2011 and 30 April 2014.

We considered:

- exposed: vaccinated child from the cohort;

- non-exposed: non-vaccinated child from the cohort;

- sick: every child from the cohort with a stool positive for RV, identified by ELISA;

- not sick: every child from the cohort with a stool negative for RV (by ELISA).

Non-inclusion criteria: a case was not included in the cohort study if they presented one or more of the following criteria:
- unspecified date of the beginning of the diarrhoea,

- gastroenteritis occurring during hospitalization for other disease,

- had unknown laboratory results,

- had unknown vaccine status.

The study flow chart (Figure 1) shows the case selection process.

\section{Data analysis}

We used Ministry of Health data, comprising monthly aggregated data of AGE cases according to age group, degree of dehydration, region and location (rural or urban) to study the trends of AGE (11). We also used the RVGE surveillance data collected from the Oriental region sentinel site. Were collected the demographical, epidemiological and clinical characteristics of all children who presented with RVGE. The stool samples were analysed at the RV national laboratory using the ELISA technique; this laboratory used the polymerase chain reaction technique for RV genotyping. We merged both clinical and biological data using the unique identification number.

To calculate the cumulative incidence of AGE in different regions, we used as denominator the population at risk, i.e. children under 5 years old, extracted from the Moroccan Ministry of Health annual statistics report covering 2011-2014.

For the cohort analysis, the association between vaccination and confirmed RVGE was estimated using the relative risk and its 95\% confidence interval.

We estimated the vaccine effectiveness (VE) according to the formula VE = 1-RR (12) as well as the preventive fraction among all vaccinated AGE cases in the Oriental region.

We analysed the data using Excel and EpiInfo, 3.5.4, software. The proportions were compared using parametric and non-parametric tests. A test was considered statistically significant when the $P$-value was $<0.05$.

\section{Ethical considerations}

Confidentiality was respected as the data used were provided anonymously by the Ministry of Health's epidemiological surveillance service.

\section{Results}

\section{Step 1: Trend of AGE at the primary health care centres}

\section{Time-trend}

Between 2007 and 2012 (2010 was excluded since this was the year vaccination was implemented, with some disparity between regions), 2249536 children under 5 years were seen in primary health care facilities for an AGE episode. We counted 1369159 between 2007 and 2009 and 880377 between 2011 and 2012.

The number of AGE cases decreased by $5.2 \%$, from 461858 cases in 2007 to 437861 in 2012. This reduction had 
Figure i Study flow chart: selection of the study population at the Oujda rotavirus surveillance sentinel site

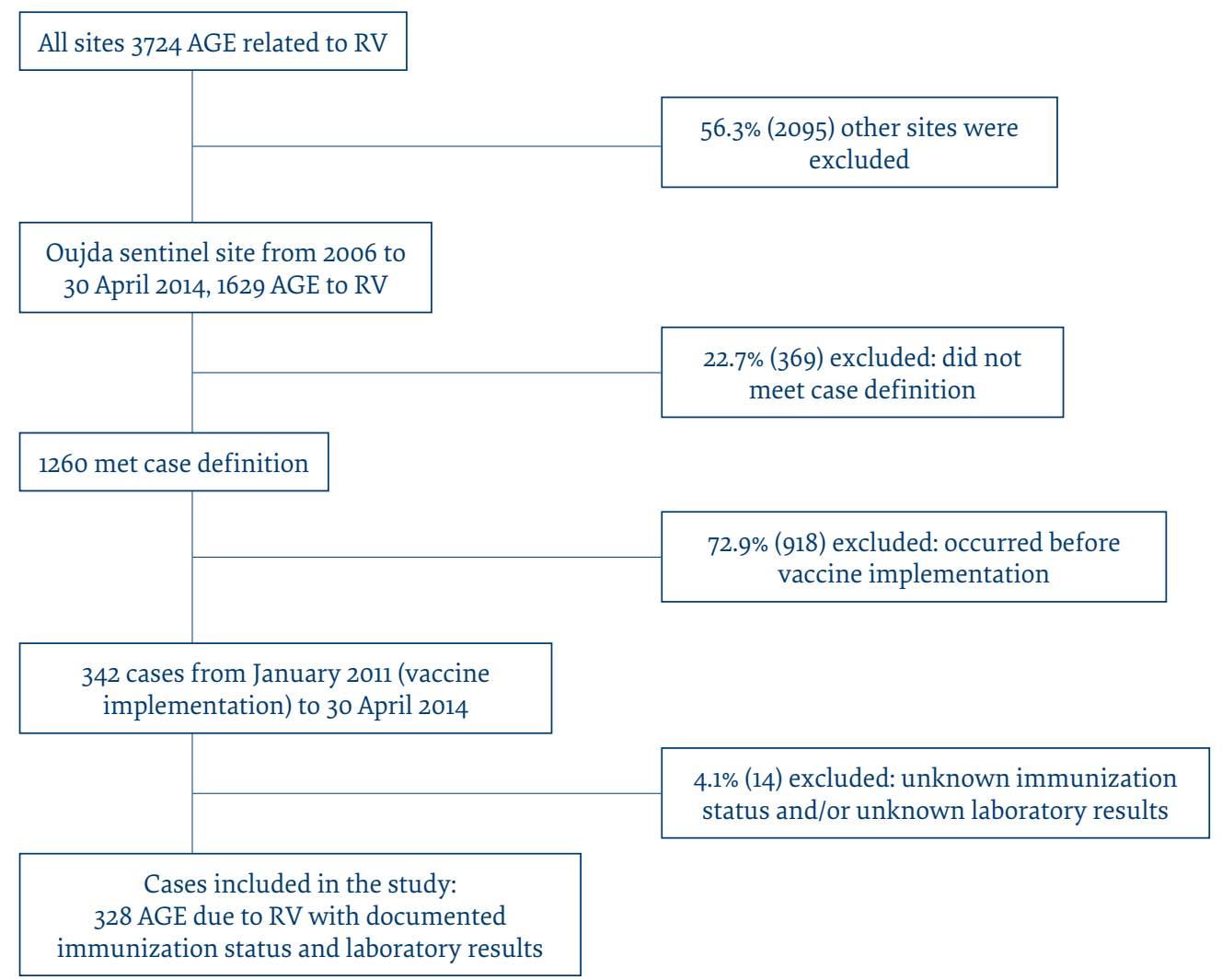

been noticed during the period before the introduction of the anti-RV vaccine and afterwards. Indeed, between 2007 and 2009, the yearly reduction was 7697 AGE cases, while between 2011 and 2012, it was about 4655 .

\section{Age trend}

During the study period, 827523 (36.8\%) cases were diagnosed among children aged o-11 months, 754893 (33.6\%) among children aged 12-23 months and 667120 (29.6\%) among children aged 24-59 months. Compared with the age group 12-23 months, fewer cases were observed among those aged 0-11 months, however, the 24-59 months age group registered a greater number of cases between 2007 and 2012 (Figure 2).

The proportion of AGE cases where no dehydration was observed was $98.7 \%$ between 2007 and 2009 and 98.9\% between 2011 and 2012. The proportion of moderate dehydration cases decreased by $1.2 \%$ before vaccine implementation and by $1.1 \%$ afterwards. The proportion of cases with severe dehydration varied between $0.2 \%$ (2007-2009) and 0.1\% (2011-2012).

\section{Geographical distribution of cases}

All regions of Morocco recorded cases of AGE. The Tadla Azilal region in central Morocco experienced the highest incidences during the study period with a maximum of $22801.6 / 100000$ children under 5 years in 2008 and $21386.3 / 100000$ in 2011. This incidence was lower, not exceeding 10000 cases of AGE/100 ooo children under
5, in the Lâayoune-Boujdour-Sakia Lhamra region in the south of the country throughout the study period.

The number of AGE cases was higher in the rural than the urban area between 2007 and 2012. A slight decrease in the number of rural cases was noticed in 2011 and 2012. There was no change in AGE trend in the urban area.

\section{Step 2: Evolution of RVGE in the Oriental region sentinel site}

Between June 2006 and April 2014, the total number of RVGE cases (suspected or confirmed) that needed a consultation at the primary care level or a hospital admission in the Oriental region sentinel site (primary health care centre or hospital) was about 1260. Among these, 1249 (99.1\%) had a documented laboratory result.

The proportion with confirmed RVGE was 37.0\% (334/902) between May 2006 and December 2009 versus 31.1\% (108/347) between January 2011 and April 2014. The decrease was only statistically significant for the age group 0-11 months, reducing from $38.8 \%$ (192/495) to 28.1\% (52/185) ( $P=0.009)$.

The proportion of positive cases in the hospital setting, went down from 38.1\% (324/850) between June 2006 and December 2009 to 35.1\% (99/282), between January 2011 and April 2014. Thus, admissions related to positive RV decreased by $7.8 \%(P=0.37)$.

The proportion of RVGE-confirmed cases admitted at the sentinel hospital in the Oriental region decreased from $3.42 \%$ to $1.30 \%$ after the introduction of the vaccine. This reduction was $73.5 \%$ for the age group 0-11 months. 
Figure 2 Number of acute gastroenteritis cases among children under 5 years old reported in the hospital and primary health care facilities, Morocco, before and after the vaccine introduction into the National Immunisation Programme 2007-2012 (data source: Ministry of Health, Rabat) (arrow indicates vaccine introduction)

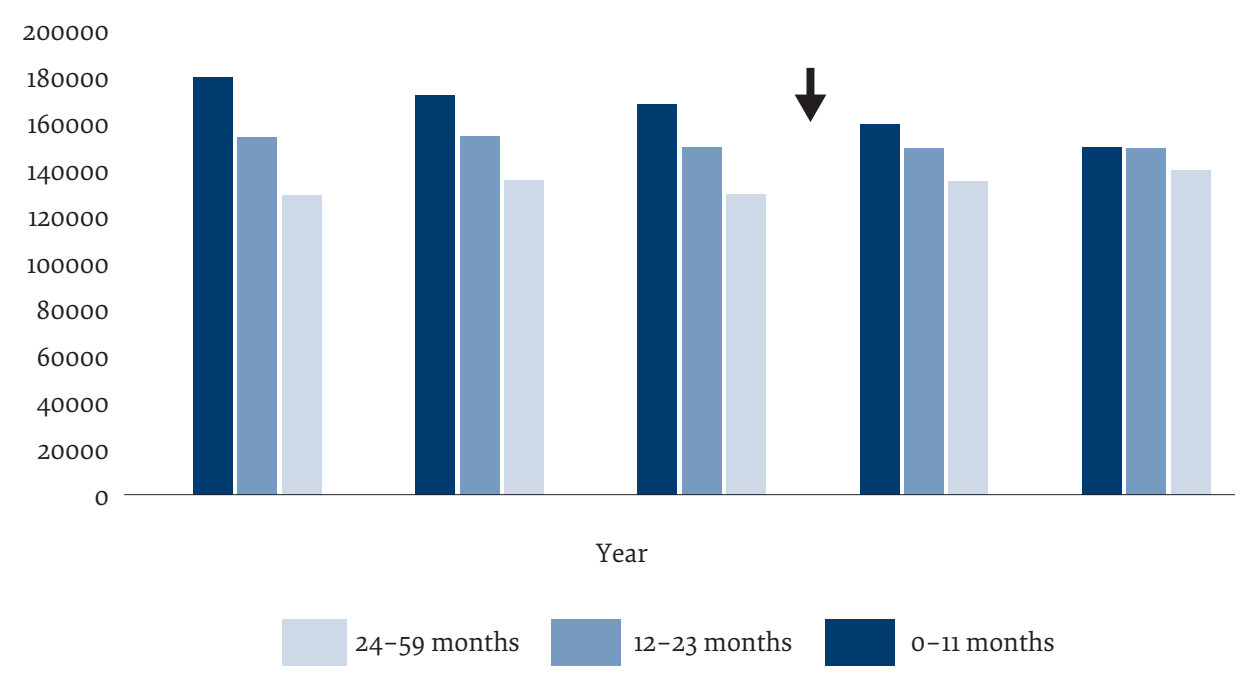

No confirmed RVGE case has been hospitalized since August 2012.

The most significant variations between the periods before and after the RV vaccine implementation were observed in the proportion of hospital admissions for AGE and in the degree of dehydration (Table 2).

\section{Step 3: Vaccine effectiveness analysis}

Our cohort from the sentinel surveillance site in the Oriental region comprised 328 cases (Figure 1). The median age was 11 months (Q1: 5 months; Q3: 19 months) and the male/female ratio was 1.34 . Around $80 \%$ of the cases (263/328) were admitted to the hospital and around 95\% $(312 / 328)$ were from rural areas. The mean duration of the diarrhoea was 2.9 (standard deviation 2.0) days and vomiting was reported in just over $75 \%$ (247/328) of cases. Just over $23 \%(76 / 328)$ did not show any sign of dehydration whereas $25 \%(82 / 328)$ were moderately dehydrated and $51.8 \%(170 / 328)$ severely dehydrated.

In our cohort, $14.9 \%$ (49/328) were vaccinated (Table 3). Among the vaccinated children, $14.3 \%$ (7/49) were diagnosed RV-positive, versus 33.3\% (93/279) for the non-vaccinated children (Table 4). The vaccine was able to prevent $57.1 \%$ (95\% CI: 13-79) of sickness among the vaccinated children in our cohort. The vaccination coverage (2nd dose) in the Oriental region in 2013 was of $87 \%$. Thus, the vaccine was able to prevent $49.7 \%$ (preventive fraction $=49.7 \%$; 95\% CI: $11.3-68.7$ ) of RVGE cases for children under 5 years who present an AGE in this region. We observed that the number of patients decreased between 2011 and 2013 as immunization coverage increased.

The proportion of the $\mathrm{GlP}[8]$ genotype decreased during the study period from $56 \%$ to $40 \%(P<0.001)$, while the $\mathrm{G}_{2} \mathrm{P}[4]$ genotype increased from $13 \%$ to $21 \%(P=0.015)$.

\section{Discussion}

In Morocco, the number of outpatients with AGE in primary health care facilities decreased by $5.2 \%$ between 2007 and 2012. This decrease began before the introduction of the anti-RV vaccine, and was probably due to improvements in hygiene conditions, the promotion of breastfeeding and other public health interventions. For this study, we only had access to the data of the 2 years following the vaccine introduction, so we were not able to estimate absolutely the attributable incidence decrease for the vaccine; otherwise, we would have used a modelling time series to determine the incidence trends over time (13-15).

The decrease in number of cases has been more significant in the age group 0-11 months. The age group 12-23 months, which included vaccinated and nonvaccinated children, did not experience any change. The age group 24-59 months was not vaccinated: they were over the age limit for the first anti-RV vaccine dose at the time of vaccine introduction in 2010. This may explain the absence of a decrease in the number of cases for the age groups 12-23 months and 24-59 months. Similar results have been reported in developing countries $(2,14,16,19,20)$, where the greatest reduction in number of deaths was observed among children younger than 2 years, who had the highest rates of vaccination.

In the Oriental region of Morocco, the vaccination coverage rate ( 2 doses) with the monovalent vaccine within the national immunization programme increased from $68 \%$ in 2011 to $83 \%$ in 2012 , and reached $87 \%$ in 2013 . The proportion of RV positivity in this region between 2006 and 2009 was $37.0 \%$. In the sentinel hospital, it was $38.1 \%$, similar to the result obtained in another study conducted in Morocco over the same period (39.4\%) (3). The vaccination reduced by $56.7 \%$ the proportion of confirmed RVGE cases among children under 5 years old who were admitted in the sentinel hospital in the Oriental 
Table 2 Distribution of rotavirus (RV) positive acute gastroenteritis cases before and after the introduction of the vaccine in the Moroccan National Immunization Programme, Oujda surveillance sentinel site, June 2006-April 2014

\begin{tabular}{|c|c|c|c|}
\hline \multirow[t]{2}{*}{ Characteristic } & $\begin{array}{l}\text { Before introduction of RV vaccine }^{a} \\
\qquad(n=334)\end{array}$ & $\begin{array}{l}\text { After introduction of RV vaccine }{ }^{b} \\
\qquad(n=108)\end{array}$ & P-value \\
\hline & $\%$ & $\%$ & \\
\hline \multicolumn{4}{|l|}{ Age (months) } \\
\hline $0-11$ & 57.5 & 48.1 & \multirow[t]{3}{*}{0.207} \\
\hline $12-23$ & 21.9 & 28.7 & \\
\hline $24-59$ & 20.7 & 23.1 & \\
\hline \multicolumn{4}{|l|}{ Sex } \\
\hline Male & 62.0 & $57 \cdot 4$ & 0.398 \\
\hline \multicolumn{4}{|l|}{ Area $^{c}$} \\
\hline Urban & 92.5 & 88.9 & \multirow[t]{2}{*}{0.240} \\
\hline Rural & 7.5 & 11.1 & \\
\hline \multicolumn{4}{|l|}{ Admission structure } \\
\hline Primary care services & 3.0 & 8.3 & \multirow[t]{2}{*}{$0.022^{*}$} \\
\hline Hospital & 97.0 & 91.7 & \\
\hline \multicolumn{4}{|l|}{ Clinical symptoms } \\
\hline Fever & 77.5 & 70.4 & 0.130 \\
\hline Vomiting & 91.9 & 91.7 & 0.934 \\
\hline Dehydration absent & 7.8 & 11.1 & \multirow[t]{3}{*}{$<0.001^{*}$} \\
\hline Moderate dehydration & 85.6 & 31.5 & \\
\hline Severe dehydration & 6.6 & 57.4 & \\
\hline \multicolumn{4}{|l|}{ Evolution } \\
\hline Recovered & 99.4 & 100 & \multirow[t]{2}{*}{0.571} \\
\hline Died & 0.6 & o. & \\
\hline Mean (SD) duration of diarrhoea (days) & $2.50(1.06)$ & $2.28(0.98)$ & 0.051 \\
\hline
\end{tabular}

aTune 2006-December 2009.

banuary 2011-April 2014.

'The data were available for 333/334patients before the introduction of the RV vaccine.

$S D=$ standard deviation

* Statistically significant.

region. Better results have been obtained in developed countries such as the United States of America (USA) (96\%) and Belgium (65-83\%) using a monovalent vaccine $(3,17,18)$. This decrease could be partly attributed to the slackening of the sentinel monitoring site in the Oriental region, even though it is more efficient compared with the other sentinel sites in recruiting cases. We found that RVGE was more frequent in males before and after the vaccination, but with no significant association between the disease and sex, as seen in other studies in Morocco and the USA $(3,17)$.

In the Oriental region, $57.5 \%$ of children were under the age of one year before the introduction of the vaccine and $48.1 \%$ after. Greater vaccine effectiveness was registered in this age group throughout the world $(2,16-19)$. The decrease in the proportion of positivity was greater for this age group, similar to in Mexico where the same age group experienced a significant decrease in diarrhoea-related hospitalizations $(16,20)$.

Regarding the severity of the disease, a reduction in confirmed RVGE mortality was recorded, no deaths linked to RV have been reported in the Oriental region after introduction of the vaccine. Studies in Mexico and
Brazil showed a large decrease in diarrheal mortality after rotavirus vaccination $(14,16,20)$.

The variation of circulating genotypes in Morocco between 2006 and 2007 has been well documented (4). After the introduction of the anti-RV vaccine, the proportion of the $\mathrm{G}_{1} \mathrm{P}[8]$ genotype decreased (40\%), while the $\mathrm{G}_{2} \mathrm{P}[4]$ increased significantly from $13 \%$ to $21 \%$. A study conducted in Belgium showed an increase in $\mathrm{G}_{2} \mathrm{P}[4]$ in children vaccinated with the monovalent vaccine (21). Unfortunately, as the genotyping data were aggregated, we were not able to study the genotype variation according to vaccination status.

The vaccine effectiveness in the cohort study was of 57.1\%.This relatively low value could be due to the fact that the $\mathrm{G}_{2} \mathrm{P}[4]$ strain was prevalent in the Oriental region while the vaccine used within the national immunization programme was monovalent and essentially covered the $\mathrm{GlP}[8]$ genotype. This vaccine effectiveness in our cohort was similar to findings from some African countries (19). In the USA and in Europe, effectiveness exceeded $90 \%$ $(17,18,21)$. 


\begin{tabular}{|c|c|c|c|}
\hline Patients characteristic & $\begin{array}{c}\text { Vaccinated } \\
n=49(14.9 \%) \\
(\%)\end{array}$ & $\begin{array}{c}\text { Not vaccinated } \\
n=279(85.1 \%) \\
\text { (\%) }\end{array}$ & $P$-value \\
\hline \multicolumn{4}{|l|}{ Age (months) } \\
\hline $0-11$ & 67.4 & 50.2 & \multirow[t]{3}{*}{$0.001^{*}$} \\
\hline $12-23$ & 30.6 & 24.7 & \\
\hline $24-59$ & 2.0 & 25.1 & \\
\hline \multicolumn{4}{|l|}{ Sex } \\
\hline Male & 57.1 & $57 \cdot 4$ & 0.979 \\
\hline \multicolumn{4}{|l|}{ Area } \\
\hline Urban & 100 & 94.3 & \multirow[t]{2}{*}{0.086} \\
\hline Rural & 0 & 5.7 & \\
\hline \multicolumn{4}{|l|}{ Admission structure } \\
\hline Primary care services & 67.4 & 11.5 & \multirow[t]{2}{*}{$<0.001^{*}$} \\
\hline Hospital & 32.7 & 88.5 & \\
\hline \multicolumn{4}{|l|}{ Clinical symptoms } \\
\hline Fever & 30.6 & 66.0 & $<0.001^{*}$ \\
\hline Vomiting & 36.7 & 82.1 & \multirow[t]{2}{*}{0.934} \\
\hline Dehydration absent & 69.4 & 15.1 & \\
\hline Moderate dehydration & 2.0 & 29.0 & \multirow[t]{2}{*}{$<0.001^{*}$} \\
\hline Severe dehydration & 28.6 & 55.9 & \\
\hline \multicolumn{4}{|l|}{ Outcome } \\
\hline Recovered & 100 & 100 & \\
\hline Died & 0 & 0 & \\
\hline Mean (SD) duration of diarrhoea (days) & $3.7(1.5)$ & $2.4(1.1)$ & $<0.001^{*}$ \\
\hline
\end{tabular}

*Statistically significant

There are some limitations in this study in that we studied RVGE cases only in the sentinel site of the Oriental region, which is the most efficient in recruiting cases, rather than other sites where there were many missing data, mostly concerning vaccination status. The choice of the study population among children who all presented an AGE constitutes a selection bias. Vaccine effectiveness would have been estimated more accurately if we had used the test negative design and estimated the odds ratio instead of the relative risk (22). We were not able to study the correlation between the vaccination status and the circulating strains in Morocco as the data concerning the genotypes were aggregated. Despite these limitations, this study has allowed us to compare the data collected by the Ministry of Health from both primary health care facilities and the RVGE sentinel surveillance site based on virological confirmation to estimate the global effect of the vaccine on AGE in terms of number of cases and severity.

Finally, efforts should be made to ensure the completeness of the data, continue the genotype monitoring and ensure the sustainability of rotavirus vaccine into the national immunization programme. A new evaluation of the vaccine strategy against rotavirus must be conducted, especially after switching to the pentavalent vaccine, and the surveillance system for this virus must be strengthened to allow such evaluation.

\begin{tabular}{|c|c|c|c|c|c|}
\hline \multirow[t]{2}{*}{ Status } & $\begin{array}{l}\text { Positive } \\
\text { rotavirus }\end{array}$ & $\begin{array}{l}\text { Negative } \\
\text { rotavirus }\end{array}$ & Total & Relative risk & $\begin{array}{l}\text { 95\% confidence } \\
\text { interval }\end{array}$ \\
\hline & No. (\%) & No. (\%) & & & \\
\hline Vaccinated & $7(14.3)$ & $42(85.7)$ & 49 & 0.43 & $0.21-0.87$ \\
\hline Not vaccinated (R) & $93(33.3)$ & $186(66.7)$ & 279 & - & - \\
\hline Total & 100 & 228 & 328 & - & - \\
\hline
\end{tabular}




\section{Acknowledgement}

The authors wish to thank the director of the Oriental region for the contribution in facilitating access to the data. We also thank Dr Benhafid, who provided the national laboratory data from the rotavirus surveillance network, and Mme Tarhda Zineb, who helped to translate the first draft of the paper.

Funding: None.

Competing interests: None declared.

\section{Tendances de la gastroentérite aiguë à rotavirus chez les enfants de moins de cinq ans avant et après l'introduction du vaccin (Maroc) 2006-2014}

\section{Résumé}

Contexte: Au Maroc, la gastroentérite aiguë chez l'enfant constitue un problème de santé publique. Depuis 1987, plusieurs stratégies ont été menées par le ministère de la Santé marocain pour réduire la charge de morbidité associée, dont l'introduction du vaccin antirotavirus dans le programme national de vaccination en 2010.

Objectifs : Évaluer l'impact du vaccin antirotavirus chez les patients ambulatoires et hospitalisés âgés de moins de cinq ans qui sont atteints de gastroentérite aiguë.

Méthodes : Nous avons mené des études descriptives et une étude de cohorte rétrospective en utilisant les données du système de la surveillance sentinelle hospitalière et du registre national de la surveillance ambulatoire de la gastroentérite aiguë de 2006 à 2014. Ceci inclut notamment la période précédant et suivant l'administration du vaccin antirotavirus aux enfants de moins de cinq ans.

Résultats: La diminution du nombre de cas était d'environ 5,2\%, principalement chez les enfants âgés de 0 à 11 mois. La proportion de gastroentérite aiguë à rotavirus est passée de $37,0 \%$ à $31,1 \%$ après l'introduction du vaccin ; cette diminution était statistiquement significative chez les enfants âgés de 0 à 11 mois $(38,8 \%$ à $28,1 \% ; p=0,009)$. La proportion de gastroentérite aiguë à rotavirus parmi les patients hospitalisés est passée de $97,0 \%$ à $91,7 \%(p=0,022)$. Les cas de maladie diarrhéique sans déshydratation ont augmenté, passant de 7,8\% à $11,1 \%(p<0,001)$; la gastroentérite aiguë à rotavirus était 2,3 fois plus fréquente chez les enfants non vaccinés. L'efficacité vaccinale a été estimée à $57 \%$. La proportion d'infections de génotype G1P[8] a diminué après l'introduction du vaccin antirotavirus (de $56 \%$ à $40 \%$; $p<0,001$ ), tandis que le génotype G2P[4] est devenu plus fréquent (de $13 \%$ à $21 \% ; p=0,015$ ).

Conclusions: L'introduction de la vaccination antirotavirus dans le programme national de vaccination du Maroc a permis une réduction significative de l'incidence et de la gravité de la la gastroentérite aiguë à rotavirus chez les enfants de moins de cinq ans.

$$
\begin{aligned}
& \text { التجاهات التهاب المعدة والأمعاء الحاد الناجم عن الفيروس العجليّ في الأطفال دون سن الخامسة قبل استحداث } \\
& \text { اللقاح وبعده، المغرب، 2006-2014 }
\end{aligned}
$$

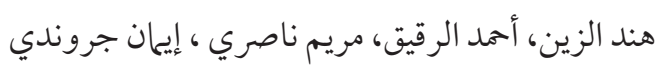

$$
\begin{aligned}
& \text { الخلاصة }
\end{aligned}
$$

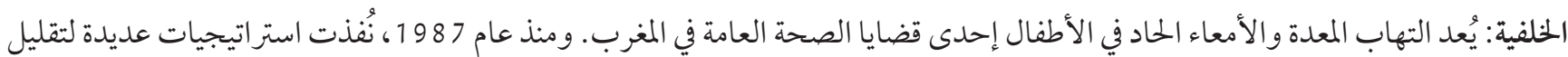

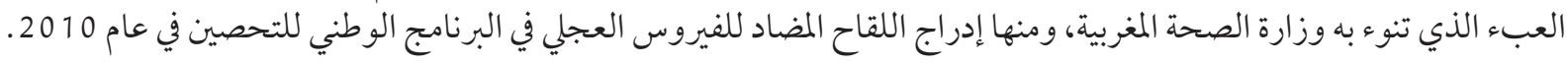
الأهداف: هدفت هذه الدراسة الى تقييم أثر اللقاح المضاد للفيروس العجلي على المرضى الخارجيين والمرضى الداخليين المصابين بالتهاب المعدة

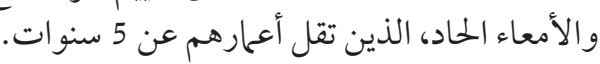

طرق البحث: أجرينا دراسات وصفية ودراسة أترابية بأثر رجعي باستخدام بيانات من نظام الترصد المخفري للمستشفيات، و السجل الوطني للترصد الإسعافي لالتهاب المعدة والأمعاء الحاد، في الفترة بين عامَي المَي

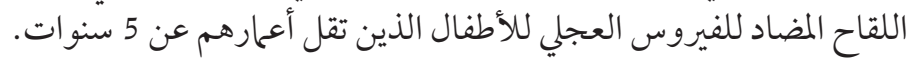

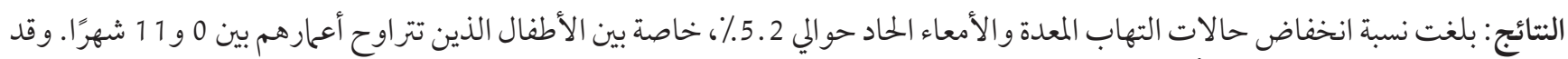

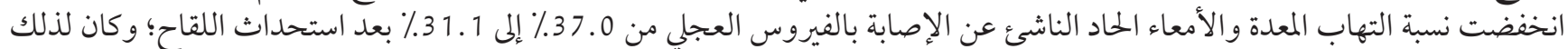

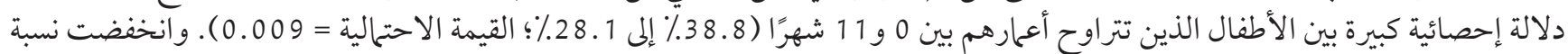

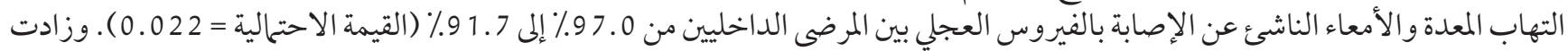




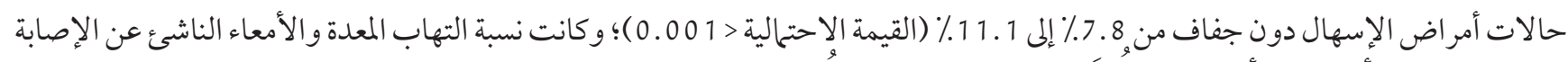

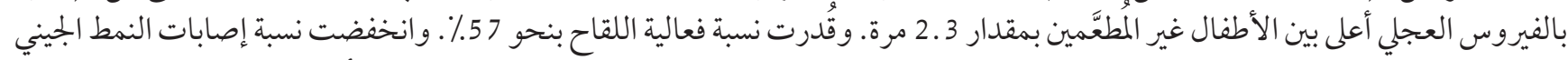

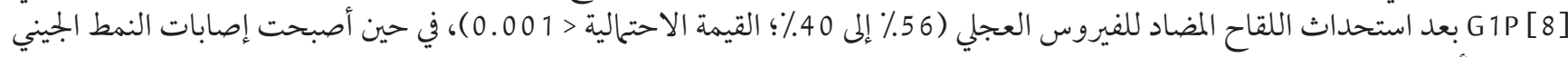

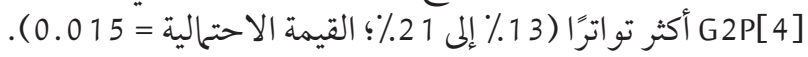

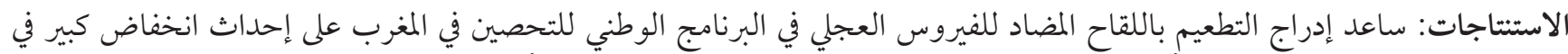

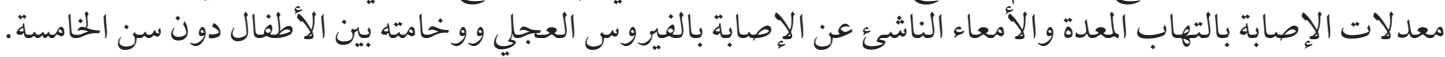

\section{References}

1. Khoury H, Ogilvie I, El Khoury AC, Duan Y, Goetghebeur MM. Burden of rotavirus gastroenteritis in the Middle Eastern and North African pediatric population. BMC Infec Dis. 2011;11:9. doi:10.1186/1471-2334-11-9

2. Rotavirus vaccines. WHO position paper - January 2013. Wkly Epidemiol Rec. 2013; 88(5):49-64. PMID:23424730

3. Benhafid M, Youbi M, Klena JD, Gentsch JR, Teleb N, Widdowson MA, et al. Epidemiology of rotavirus gastroenteritis among children < 5 years of age in Morocco during 1 year of sentinel hospital surveillance, June 2006-May 2007. J Infect Dis. 2009 Nov 1;200(Suppl. 1):S70-5. doi:10.1086/605048

4. Benhafid M, Elomari N, El Quazoui M, Meryam AI, Rguig A, Filali-Maltouf A, et al. Diversity of Rotavirus strains circulating in children under 5 years of age admitted to hospital for acute gastroenteritis in Morocco, June 2006 to May 2009, J Med Virol. 2013;85(2):354-62. doi:10.1002/jmv.23445

5. Benhafid M, Rguig A, Trivedi T, Elqazoui M, Teleb N, Mouane N, et al. Monitoring of rotavirus vaccination in Morocco: establishing the baseline burden of rotavirus disease. Vaccine. 2012 Oct 12;30(46):6515-20. doi:10.1016/j.vaccine.2012.08.058

6. Aghoutane M. Evaluation du système de surveillance des gastroentérites aigues à Rotavirus chez l'enfant de moins de 5 ans. Mémoire de Master en Santé Publique. CDS INAS; 2012 (ensp.sante.gov.ma, accessed 23 October 2017).

7. National Immunization Programme. [Practical aspects of vaccination, training manual for health professionals]. Rabat: Ministry of Health; 2013 (in French).

8. Benhafid M, Elomari N, AzzouziIdrissi M, Rguig A, Gentsch JR, Parashar U, Elaouad R. Effect of monovalent rotavirus vaccine on rotavirus disease burden and circulating rotavirus strains among children in Morocco. J Med Virol. 2015 Jun;87(6):944-53. doi:10.1002/jmv.24122

9. Prise en charge intégrée de l'enfant. Directives de prise en charge de l'enfant de moins de cinq ans. Rabat: Ministère de la Santé; (https://www.sante.gov.ma/Publications/Guides-Manuels/Documents/Guid_COUV_Protocol_PCIE_EM_RG_Nov17-1.pdf, accessed 23 December 2020).

10. Coordinated Rotavirus Surveillance Network. Geneva: World Health Organization; 2007 (http://www.who.int/immunization/ monitoring_surveillance/resources/RV_Case_Defs, accessed 18 April 2014).

11. Santé en chiffres 2014 édition. Rabat: Ministry of Health; 2015 (https://www.sante.gov.ma/Publications/Etudes_enquete/Pages/ default.aspx, accessed 27 December 2020).

12. Orenstein WA, Bernier RH, Dondero TJ, Hinman AR, Marks JS, Bart KJ, et al. Field evaluation of vaccine efficacy. Bull World Health Organ. 1985;63:1055-68. PMID:3879673

13. Doll MK, Quach C, Buckeridge DL. Evaluation of the impact of a rotavirus vaccine program on pediatric acute gastroenteritis hospitalizations: estimating the overall effect attributable to the program as a whole and as a per-unit change in rotavirus vaccine coverage. Am J Epidemiol. 2018;187(9):2029-37. doi:10.1093/aje/kwyo97

14. do Carmo GM, Yen C, Cortes J, Siqueira AA, de Oliveira WK, Cortez-Escalante JJ, Lopman B, et al. Decline in diarrhea mortality and admissions after routine childhood rotavirus immunization in Brazil: a time-series analysis. PLoS Med. 2011;8(4):e1001024. doi:10.1371/journal.pmed.1001024

15. Hungerford D, Vivancos R, Read JM, Bonnett LJ, Bar-Zeev N, Iturriza-Gómara M, et al. Mitigating bias in observational vaccine effectiveness studies using simulated comparator populations: application to rotavirus vaccination in the UK. Vaccine. 2018 Oct 29;36(45):6674-82. doi:10.1016/j.vaccine.2018.09.051

16. Richardson V, Hernandez-Pichardo J, Quintanar-Solares M, Esparza-Aguilar M, Johnson B, Gomez-Altamirano CM, et al. Effect of rotavirus vaccination on death from childhood diarrhoea in Mexico. N Engl J Med. 2010 Jan 28;362(4):299-305. doi:10.1056/ NEJMoaogo5211

17. Burnett E, Jonesteller CL, Tate JE, Yen C, Parashar UD. Global impact of rotavirus vaccination on childhood hospitalizations and mortality from diarrhea. J Infect Dis. 2017 Jun 1;215(11):1666-72. doi:10.1093/infdis/jix186

18. Karafillakis E, Hassounah S, Atchison C. Effectiveness and impact of rotavirus vaccines in Europe, 2006-2014. Vaccine. 2015 Apr 27;33(18):2097-107. doi:10.1016/j.vaccine.2015.03.016

19. Armah GE, Sow SO, Breiman RF, Dallas MJ, Tapia MD, Feikin DR, et al. Efficacy of pentavalent rotavirus vaccine against severe rotavirus gastroenteritis in infants in developing countries in sub-Saharian Africa: a randomised, double-blind, placebo-controlled trial. Lancet 2010;376(9741):606-14. doi:10.1016/So140-6736(10)60889-6 
20. Quintanar-Solares M, Yen C, Richardson V, Esparza-Aguilar M, Parashar UD, Patel MM. Impact of rotavirus vaccination on diarrhea-related hospitalizations among children under 5 years of age in Mexico. Pediatr Infect Dis J. 2011;30(1 Suppl.):S11-5. doi:10.1097/INF.obo13e3181fefb32

21. Matthijnssens J, Zeller M, Heylen E, De Coster S, Vercauteren J, Braeckman T, et al. Higher proportion of G2P[4] rotaviruses in vaccinated hospitalized cases compared with unvaccinated hospitalized cases, despite high vaccine effectiveness against heterotypic G2P [4] rotaviruses, Clin Microbiol Infect. 2014 Oct;20(10):O702-10. doi:10.1111/1469-0691

22. Fukushima W, Hirota Y. Basic principles of test-negative design in evaluating influenza vaccine effectiveness. Vaccine. 2017 Aug 24;35(36):4796-800. doi:10.1016/j.vaccine.2017.07.003 